\title{
The Effect of Extracellular Matrix Patch on Femoral Artery after Endarterectomy
}

Sani Penovic ${ }^{*}$, Ivana Stula ${ }^{2}$, Teo Boric ${ }^{1}$ and Zenon Pogorelic ${ }^{3}$

${ }^{1}$ Clinic for Surgery, University Hospital Centre Split, Croatia

${ }^{2}$ Clinical Institute for Diagnostic and Interventional Radiology, University Hospital Centre Split, Croatia

${ }^{3}$ Clinic for Children Surgery, University Hospital Centre Split, Croatia

\begin{abstract}
Background: CorMatrix is a unique extracellular matrix (ECM) that is made from porcine small intestinal submucosa (SIS). It is processed to remove cells but leaving molecules such as collagen, growth factors, proteins, and cytokines. This biomaterial does not calcify when surgically implanted, without any or with minor inflammatory reaction, supports native tissue repair by providing a bioscaffold that gives a patient's own cells to repopulate and repair damaged tissue. It has been used for pericardial reconstruction, cardiac tissue repair, vascular applications and wound treatment.

Methods: We used CorMatrix porcine SIS-ECM on four patients after endarterectomy of femoral arteries as patch angioplasty. They had a control examination by color Doppler ultrasound one year after the operation.

Results: One of the patients died two days after the operation due to cardiac arrest. Two patients had a normal patency through the common femoral artery with CorMatrix. Spectral analysis showed normal triphasic flow pattern with adequate velocity. The third patient, who had stenosis of the external iliac artery in distal part before the operation, now had restenosis. There was patency through the common femoral artery and CorMatrix with only marginal wall thickening.
\end{abstract}

Conclusion: CorMatrix porcine SIS-ECM proved as a good and safety patch.

Keywords: Peripheral artery disease; Femoral endarterectomy; Extracellular matrix; CorMatrix, Patch angioplasty; Color doppler ultrasound

\section{Introduction}

CorMatrix is the extracellular matrix (ECM) bioscaffold made from porcine small intestinal submucosa (SIS) (Figure 1) [1]. It is used in clinical applications as a scaffold tissue repair [2-4]. It seems to be the "next-generation" cardiovascular tissue engineering because of its easy handling, remodeling, deficiency of immunogenicity and a potential to promote native tissue growth [5]. CorMatrix is processed in a way that it removes cells leaving a complex 3 -dimensional structural matrix behind. The stem cells from a patient migrate into the ECM and integrate with the result of permanent tissue repair without leaving foreign material [6]. The material retains collagen, growth factors, proteins, and cytokines which have important roles in host tissue repair and remodeling $[3,7,8]$. It has tensile strength and resistance to thrombosis [9]. As a natural biomaterial that is replaced by the patient's own cells, it is resistant to infection and scars [10,11].

Peripheral artery disease (PAD) is defined as any pathologic process causing obstruction to blood flow in the arteries and is a common manifestation of atherosclerosis [12]. Age and gender-adjusted risk factors associated with the development of PAD are similar to the traditional risk factors for atherosclerosis, including cigarette smoking, diabetes, hyperlipidemia, hypertension, and chronic renal insufficiency [12-14]. Surgery is only performed in cases of severe PAD, such as intermittent claudication after less than 150-100 meters of walking, rest pain, the pain of open sores (ulcers that won't heal); or serious skin, bone, and tissue problems (gangrene) (The Fontaine classification; II b, III and IV stage). Focal steno-occlusive lesions of the common femoral artery are conventionally treated with endarterectomy (EA) usually with patch repair. Bifurcation lesions are treated with EA in conjunction with profundoplasty. Long-term patency rates of the common femoral and bifurcation EA are $95 \%$ and $89 \%$ at $3-5$ years [15]. The use of vein patches is considered to be the "gold standard" for patch closure, but newer generations of synthetic and biological materials rival outcomes associated with vein patches. The most commonly used prosthetic patching materials are polytetrafluoroethylene (PTFE) and Dacron [16]. The problems with prosthetic patches are restenosis, occlusion, pseudoaneurysm formation and infection [17-19].

In this case report, we wanted to present our patients with peripheral artery disease who had femoral endarterectomy with CorMatrix porcine SIS-ECM as patch angioplasty. After one year they had control examination with color Doppler ultrasonography.

This research was ethically approved and accepted with informed consent by the patients.

\section{Materials and Methods}

Four patients were treated with CorMatrix porcine SIS-ECM at the University Hospital Split. They had PAD (the Fontaine classification II b). After MDCT angiography was made, stenosis of the common femoral artery (CFA) with bifurcation was verified. They had an

*Corresponding author: Sani Penović, MD, Vascular Surgeon, Department of Vascular Surgery, Clinic for Surgery, University Hospital Centre Split, Spinčićeva 1 21000 Split, Croatia, Tel: 00385989270908; E-mail: sanipenovic@gmail.com

Received October 10, 2018; Accepted October 24, 2018; Published October 30 2018

Citation: Penovic S, Stula I, Boric T, Pogorelic Z (2018) The Effect of Extracellular Matrix Patch on Femoral Artery after Endarterectomy. J Vasc Med Surg 6: 371. doi: 10.4172/2329-6925.1000371

Copyright: $\odot 2018$ Penovic S, et al. This is an open-access article distributed unde the terms of the Creative Commons Attribution License, which permits unrestricted use, distribution, and reproduction in any medium, provided the original author and source are credited. 
indication of endarterectomy (EA) of the femoral artery. They all had occlusion of the superficial femoral artery (SFA). They were men, mean age 68 (from 60 to 76). Three of them had diabetes mellitus type 2, two of them had a malignant diagnosis (the neoplasm of stomach and lip), one suffered from high blood pressure, and the one had the benign tumor of a knee. They were admitted to the Department of Vascular Surgery. The operations were performed under spinal anesthesia. After incision of the femoral region (three on the left side, one on the right) the dissection of the CFA with branches was done. After general heparinization and clamping of femoral arteries, arteriotomy of the CFA was made. Stenosis of the CFA and profunda femoris artery (PFA) were identified. There was occlusion of the SFA, too. One of them had stenosis of the distal part of external iliac artery (EIA). EA of the CFA and PFA were done. One had thromboembolus in the beginning of the SFA that was treated with Fogarty catheter and distal part with EA. The patient with significant stenosis of the EIA had EA of it. After the all mentioned procedures, patch angioplasty of the CFA and PFA (profundoplasty) was performed with CorMatrix porcine SIS-ECM in the following steps. CorMatrix was hydrated in the room temperature saline for 1 minute. After soaking, it was sewed with 5-0 Prolene suture. The patient with stenosis of the EIA, had patch angioplasty of that distal part with CorMatrix. The patient with thromboembolic at the proximal part and atherosclerotic plaque at the distal part of the SFA, also had patch angioplasty of the SFA with CorMatrix. The subfascial drain was put and a wound was sewn in layers. The patients were treated with crystalline solutions, low molecular weight heparin, gastroprotective and analgetic therapy with the regular folding of the wound. The drain was pulled out on the second postoperative day. The average hospital treatment was 8 days (from 3 to 15 days).

\section{Results}

One of the patients died two days after the operation due to cardiac arrest. Other three patients were examined at the Clinic for Surgery after one, three and six months postoperatively. They did not have any complications, they were in good general condition and were able to walk. The examination was performed with the color Doppler ultrasound one year after. Two patients had a normal patency through the CFA with CorMatrix. Spectral analysis showed normal triphasic flow pattern with adequate velocity. One had normal flow through the EIA, PFA, and SFA (Figure 2). Also had one enlarged lymph node in the operated femoral region. Another had normally patency through the EIA, PFA but SFA was occluded (like it was before and after the operation). The third patient, who had stenosis of the EIA in distal part before the operation, now had restenosis. There was patency through the CFA and CorMatrix with only marginal wall thickening. Spectral

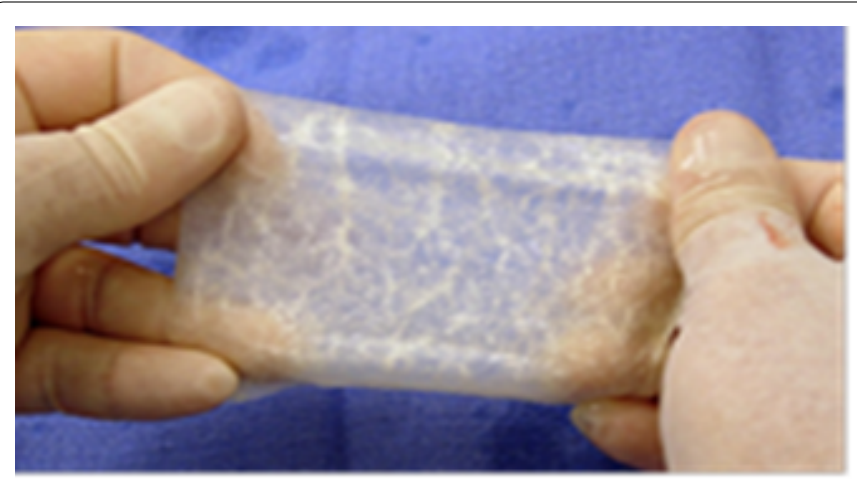

Figure 1: CorMatrix porcine SIS-ECM.

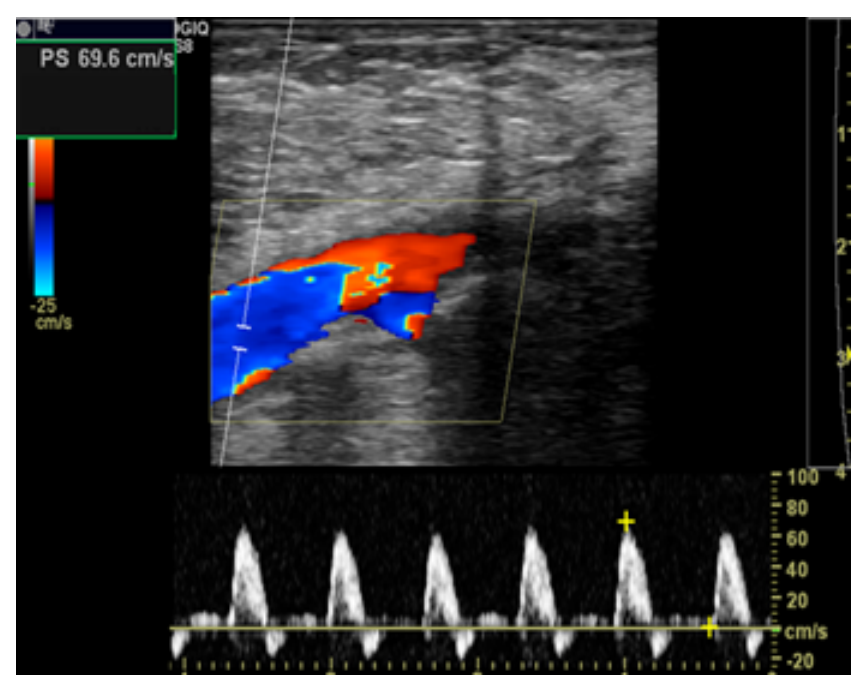

Figure 2: The normal triphasic waveforms in the common femoral artery after patch angioplasty.

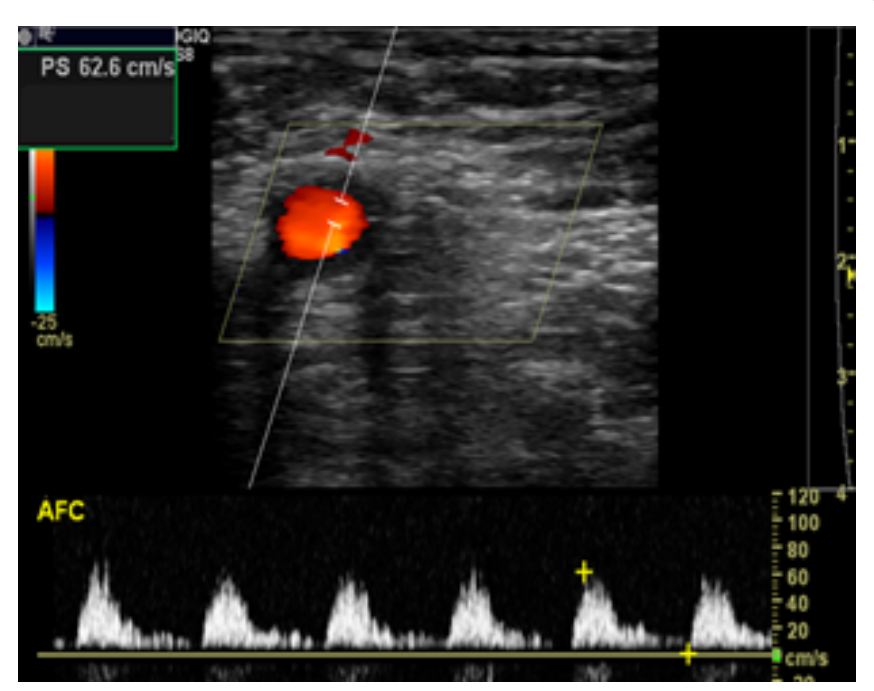

Figure 3: The biphasic flow through the common femoral artery due to the significant stenosis of the distal part of the external iliac artery.

Doppler showed low-resistance waveform due to the significant restenosis of the EIA, with the maintained velocity (PSV more than 60 $\mathrm{cm} / \mathrm{s}$ ) (Figure 3). Normal patency was through the PFA but the SFA was occluded (like it was before and after the operation).

\section{Discussion}

CorMatrix is a decellularized scaffold into which host cells migrate and remodel into new mature tissue [20]. Its main component is collagen along with adhesion glycoproteins, glycosaminoglycans, proteoglycans, matricellular proteins and growth factors [3]. Handling is easy and it does not create calcification, thickening or retraction with minor inflammation. It has been used in cardiovascular applications, including paediatric patients [21]. Several large animal studies testing this material in vascular locations have reported positive results [22-24]. The results of Nezhad et al. on pigs showed that remodeling is predominantly by fibrosis and with extensive inflammation [20]. Healing and recovery were complex, multifactorial and with chronic processes. The clinical 
studies of CorMatrix in cardiovascular surgery have few reports of complications when it is used in the low-pressure vessels, usually extracardiac environment, but when it is used at the higher pressure, the intracardiac sites such as the aortic valve complications are more likely to occur [21]. CorMatrix is used as a patch in cardiovascular operations $[21,25,26]$. In the study of Weber and al., implanted patches in the carotid position resulted in 10\% incidence of pseudoaneurysm formation [27]. It is mentioned in the studies that CorMatrix is used as a patch on the femoral artery. Dobrilovic at al. showed a high incidence of early postoperative complications including catastrophic patch disruption and pseudoaneurysm formation [28]. There were no complications in way of breaking or pseudoaneurysm in our patients.

\section{Conclusion}

In our case, CorMatrix porcine SIS-ECM proved as a good patch. For satisfactory results in the future, there should be more patients treated and compared with the control group treated by vein or synthetic patch and with inflammatory testing. Moreover, it is recommended to use it in the inflammatory area. There should be more clinical studies with the long follow-up to show the efficiency of CorMatrix porcine SIS-ESM in the treatment of patients with PAD.

\section{References}

1. Holubec T, Caliskan E, Sundermann SH, Starck CT, Plass A, et al. (2015) Use of extracellular matrix patches in cardiac surgery. J Card Surg 30: 145-148.

2. Macleod TM, Sarathchandra P, Williams G, Sanders R, Green CJ (2004) Evaluation of porcine origin acellular dermal matrix and small intestina submucosa as dermal replacements in preventing secondary skin graft contraction. Burns 30: 431-437.

3. Quart A, Nardone S, Colaneri M, Santoro G, Pozzi M (2011) Preliminary experience in the use of an extracellular matrix to repair congenital heart diseases. Interact Cardiovasc Thorc Surg 13: 569-572.

4. Witt RG, Raff G, Van Gundy J, Rogers-Ohlau M, Si MS (2013) Short-term experience of porcine small intestinal submucosa patches in pediatric cardiovascular surgery. Eur J Cardiothorac Surg 44: 72-66.

5. Badylak S, Obermiller J, Geddes L, Matheny R (2003) Extracellular matrix for myocardial repair. Heart Surg Forum 6: 20-26.

6. Badylak SF (2004) Xenogeneic extracellular matrix as a scaffold for tissue reconstructions. Transpl Immunol 12: 367-377.

7. Badylak SF, Freytes DO, Gilbert RW (2009) Extracellular matrix as a biological scaffold material: structure and function. Acta Biomatter 5: 1-13.

8. Hynes RO, Naba A (2012) Overview of the matrisome-an inventory of extracellular matrix constituents and functions. Cold Spring Harb Perspect Biol 4: a004903.

9. Badylak SF (2007) The extracellular matrix as a biologic scaffold material. Biomaterials 28: 3587-3593.

10. Shell DH, Croce MA, Cagiannos C, Jernigan TW, Edwards N, et al. (2005) Comparison of Small-Intestinal Submucosa and Expanded Polytetrafluoroethylene as a Vascular Conduit in the Presence of Gram-Positive Contamination. Ann Surg 241: 995-1004.

11. Brennan EP, Reing J, Chew D, Myers-Irvin JM, Young EJ, et al. (2006)
Antibacterial activity within degradation products of biological scaffolds composed of extracellular matrix. Tissue Eng 12: 2949-2955

12. Hirsch AT, Haskal ZJ, Hertzer NR, Bakal CW, Creager MA, et al. (2006) ACC/ AHA 2005 Practice Guidelines for the management of patients with peripheral arterial disease (lower extremity, renal, mesenteric, and abdominal aortic) a collaborative report from the American Association for Vascular Surgery/ Society for Vascular Surgery. Circulation 113: 463-654.

13. Selvin E, Erlinger TP (2004) Prevalence of and risk factors for peripheral arterial disease in the United States: results from the National Health and Nutrition Examination Survey, 1999-2000. Circulation 110: 738-743.

14. Norgren L, Hiatt WR, Dormandy JA, Nehler MR, Harris KA, et al. (2007) TASC II Working Group. Inter-Society Consensus for the Management of Peripheral Arterial Disease (TASC II). Eur J Vasc Endovasc Surg 33: 1-75.

15. Thatipelli M, Misra S (2010) Management of common femoral artery and bifurcation diseases: Clinical review. Vasc Disease Management 7: 1.

16. Berguer R, Farnan RC, Colone WM, Kowligi RR, Della Corna LV, et al. (1992) US Patent 5100422-Blood vessel patch. Google Patents.

17. Bond R, Rerkasem K, Naylor R, Rothwell PM (2004) Patches of different types of carotid patch angioplasty. Cochrane Database Syst Rev 2: CD000071.

18. Borazjani BH, Wilson SE, Fujitani RM, Gordon I, Mueller M, et al. (2003) Postoperative complications of carotid patching: pseudoaneurysm and infection. Ann Vasc Surg 17: 156-161.

19. Krishnan S, Clowes AW (2006) Dacron patch infection after carotid endarterectomy: case report and review of the literature. Ann Vasc Surg 20: 672-677.

20. Nezhad ZM, Poncelet A, Kerchove L, Fervaille C, Banse X, et al. (2017) CorMatrix valved conduit in a porcine model: long-term remodeling and biomechanical characterization. Interact CardioVasc Thorac Surg 24: 90-98.

21. Nezhad ZM, Poncelet A, Kerchove L, Fervaille C, El Khoury G (2016) Smal intestinal submucosa extracellular matrix (CorMatrix) in cardiovascular surgery: a systematic review. Interactive Cardio Vascular and Thoracic Surgery 22: 839850 .

22. Sandusky GE, Badylak SF, Morff RJ, Johnson WD, Lantz G (1992) Histologica findings after in vivo placement of small intestine submucosal vascular graft and saphenous vein grafts in the carotid artery in dogs. Am J Pathol 140: $317-$ 324

23. Boni L, Chalajour F, Sasaki T, Snyder RL (2012) Reconstruction of pulmonary artery with porcine small intestinal submucosa in a lamb surgical model: viability and growth potential. J Thorac Cardiovasc Surg 144: 963-969.

24. Fallon A, Goodchild T, Wang R, Matheny RG (2012) Remodeling of extracellular matrix patch used for carotid artery repair. J Surg Res 175: 25-34.

25. Witt RG, Raff G, Gundy J, Rogers-Ohlau M, Si MS (2013) Short-term experience of porcine small intestinal submucosa patches in paediatric cardiovascular surgery. Eur J Cardiothorac Surg 44: 72-76.

26. Madden N, Troutman D, De Marsico A (2014) Use of a small intestine submucosa extracellular matrix patch in repeated carotid endarterectomy. J Am Osteopath Assoc 114: 732-734.

27. Weber S, Annenberg A, Wright C, Braverman, Mesh C (2014) Early pseudoaneurysm degeneration in biologic extracellular matrix patch for carotid repair. J Vasc Surg 59: 1116-1118.

28. Dobrilovic N, Soukas P, Sadiq I, Goldstein L, Raman J (2017) Early complications of biologic extracellular matrix patch after use for femoral artery repair. J Vasc Surg 65: 705-710. 